\title{
BONDING PERFORMANCE OF SELF ADHESIVE FLOWABLE COMPOSITE TO DENTIN PRETREATED WITH FOUR DIFFERENT NATURAL MATRIX METALLOPROTEINASES INHIBITORS
}

\author{
El-Refai, Dina Ahmed*
}

\begin{abstract}
Objective: The study attempted to assess the effect of application of four natural matrix metalloproteinases inhibitors (proanthocyanidin, quercetin, chlorogenic acid and hesperidin); as dentin pre-treatment agents; on the shear bond strength of Vertise Flow self adhesive flowable composite to dentin.
\end{abstract}

Materials and methods: The study included five groups: Group I (control): Dentin was etched and the composite was applied without pre-treatment. Group II: Etched dentin was pre-treated with $2 \%$ proanthocyanidin prior to composite application. Group III: $2 \%$ quercetin solution was used. Group IV: $2 \%$ chlorogenic acid was used. Group V: $2 \%$ hesperidin solution was used.

Shear bond strength of 40 specimens in each group was measured; 20 specimens were tested at 24 hours, and other 20 specimens were tested after thermocycling.

Failure mode was analyzed according to Adhesive Remnant Index scoring system.

Scanning electron microscopic imaging for the composite/ dentin adhesive junction was performed.

Results: Shear bond strength testing after thermocycling revealed that group II recorded the highest value among all groups, whereas group IV recorded the least value. Concerning the failure mode; the majority of specimens of groups I and IV recorded score (1). Concerning groups II, III and $\mathrm{V}$, the majority of specimens registered score (2).

Conclusions: Proanthocyanidin can be considered a highly potent matrix metalloproteinases inhibitor to enhance and promote a satisfactory bonding stability of flowable composite to dentin, followed by quercetin and hesperidin. However, application of chlorogenic acid is not recommended.

KEY WORDS: Proanthocyanidin, quercetin, chlorogenic acid, hesperidin, shear bond strength.

\footnotetext{
* Associate Professor Biomaterials, Faculty of Dentistry, Ain Shams University, Cairo, Egypt
} 


\section{INTRODUCTION}

Flowable resin composites gained a large scale of applications in the past few years. With their low viscosities, they can be applied as pit and fissure sealants, liners beneath posterior composite restorations, restorative material in small classes I, II, and III restorations, for porcelain repair, and in blocking undercuts. In order to obtain a flowable resin composite having a self-adhesive property; acidic functional monomers as glycerol phosphate dimethacrylate (GPDM) or 4methacryloyloxyethyl trimellitic acid (4-MET) were incorporated within the self adhering resin composite.(1)

Vertise flow was introduced as self adhesive flowable composite resin. The functional monomer used in Vertise Flow according to Kerr's technical profile is the functionally acidic monomer glycerol phosphate dimethacrylate (GPDM). The bonding technology of Vertise flow uses (GPDM) to etch enamel and dentin, and can enhance wetting and penetration of the resin into dentin. Bonding of Vertise flow self adhesive composite resin to tooth structure takes place by two means: chemically as the phosphate groups of a GPDM monomer bond to the calcium ions of hydroxyapatite crystals of tooth structure. Also, micromechanical bonding occurs between the polymerized monomers of the selfadhering flowable composite resin and the collagen fibers with the formation of a hybrid layer of resin impregnation into dentin. This micromechanical bonding is achieved by the slight conditioning effect gained by the low $\mathrm{pH}$ of GPDM. This low $\mathrm{pH}$ increases to almost neutral after light curing. (2) In literature, it was reported that the functional acidic monomer GPDM can offer the formation of a thin hybrid layer (2- $\mu$ m-deep), indicating that this monomer presumably etches the dentin surface superficially, resulting in a weak bonding. ${ }^{(3)}$ For that reason, it is highly recommended to perform acid etching of dentin as a separate step before application of Vertise flow composite. Preliminary etching with $37 \%$ phosphoric acid for 15 seconds enhances the bond strength of Vertise Flow to dentin..$^{(5,6)}$

Bonding of resin-based restorative materials to dentin depends upon creating a stable hybrid layer. Poor mechanical properties induced by the degradation of the hybrid layer at the adhesive/ dentin interface contribute to the poor durability of composite restoration. Both bonding strategies (etch and rinse or self etch) may show sites of incomplete adhesive infiltration within the collagen network. Consequently, collagen fibers become susceptible to hydrolysis by endogenous enzymes; such as matrix metalloproteinases (MMPs); which is reflected as loss of hybrid layer integrity and reduction of bond strength. Thus, different approaches for MMPs inhibition were previously tried, and still considered in up-to-date researches; to improve the bonding potential of resin composites and attain a long-term bonding durability. ${ }^{(7,8)}$

Inhibiting the enzymatic activity of MMPs have been tried to improve the stability of hybrid layers. Proanthocyanidin as MMPs inhibitors could be considered in the adhesive strategy to improve the bond durability. Procyanidin can potently inhibit MMP 1, MMP 2, as well as MMP 9. The building blocks of proanthocyanidin are catechin and epigallocatechin gallate (EGCG); that have been identified as potent collagenase inhibitors. Proanthocyanidin is also rich in proline that binds to collagen in a fast reaction rate. It is available in fruits, vegetables, nuts, seeds, and extremely a main constituent in green tea. It is a natural bio-flavonoid, possessing antibacterial and antioxidant properties (superoxide scavenging) that help collagen stabilizing. In addition, it can promote type I- collagen cross- linking by inducing hydrogen bonding between protein amide carbonyl and the phenolic hydroxyl. ${ }^{(9)}$ Collagen crosslinking is a powerful mechanism to resist collagen degradation. 
Natural Antioxidants were also tried before in the literature in order to improve the adhesive junction durability. ${ }^{(10)}$ Quercetin is considered a famous flavonoid antioxidant, bearing a catechol moiety linked in position 2 to the polyhydroxylated chromen-4-one core. It is found in a large variety of dietary vegetables. Reaction of quercetin was found to be profound when dissolved in ethanol, and was suggested to occur upon deprotonation in position 7 , via a mechanism named sequential proton loss electron transfer (SPLET), to induce a strong free radical scavenging effect. This occurs by transfer of a proton to the solvent and transfer of an electron to the oxidizing compound. Also, quercetin can inhibit both MMP-2 and MMP-9 expression, mediating the interaction between both the anti-oxidation activity and expression of MMPs. ${ }^{(11-13)}$

Another antioxidant that can be tried is chlorogenic acid. Chemically; it is an ester formed between caffeic acid and quinic acid. Chlorogenic acid is considered one of the most naturally existing phenolic compounds found in numerous plant species; as coffee beans and different types of coffee, including green coffee. It is also found in some fruits such as apples, pears, eggplant, blueberries, tomatoes, strawberries, purple sweet potatoes and potatoes. ${ }^{(14)}$ Chlorogenic acid and its derivatives should receive much attention due to their high free- radical scavenging activity. Additionally, it is considered a strong MMPs- 9 inhibitor.

A different strategy to keep the integrity of hybrid layer is the use of collagen cross linkers. Hespertin7-O- rutinoside [hesperidin] is a flavonoid extract of citrus fruits. Islam et al., incorporated hesperidin (0.5 wt \%) into Clearfil SE primer. It was found that hesperidin exerted a positive influence on the resin/ dentin bond strength. The cross-linking effect of hesperidin may increase the resistance against collagen degradation. ${ }^{(15)}$ Also, it was found that hesperidin is a MMPs-9 inhibitor. It could be deduced that besides the effect of protein cross-linking, hesperidin has the capability of enhancing dentin lesion remineralization in vitro. It was speculated that the effect of hesperidin on remineralization may be related with its interaction with collagen and/or noncollagenous proteins. The stable dentinal organic matrix might hamper further diffusion of calcium and phosphate ions out of the dentinal lesion of caries, preventing further demineralization. Further, the preserved collagen matrix may be essential for the remineralization process, since it acts as a scaffold for mineral deposition. ${ }^{(16)}$

\section{AIM OF THE STUDY}

As chemical bonding of self adhesive flowable composites to dentin is considered an important parameter for obtaining an optimal adhesive junction, then it is of great interest to present new approaches for augmenting this bonding mechanism. For achieving this goal, the current study aimed to treat the etched dentin by four different natural matrix metalloproteinases inhibitors (proanthocyanidin, quercetin, chlorogenic acid and hesperidin); prior to application of Vertise Flow (self adhesive flowable composite resin) and assess their effect on the shear bond strength (SBS) of the flowable composite resin to human dentin, in addition to analyzing the failure mode. Assessment of the flowable composite resin/ dentin interface was also included in the study.

The research gap of this study: was to enhance the bonding quality and durability of Vertise Flow self adhesive flowable composite to dentin; by applying four natural matrix metalloproteinases inhibitors as pretreatment agents; prior to composite application. New collagen cross- linkers and natural antioxidants were tried in this study. The over time longevity of the composite/ dentin bond was concerned in the study.

The null hypothesis claimed that the application of the used matrix metalloproteinases inhibitors as pretreatment agents; prior to Vertise Flow self adhesive flowable composite application; would not show any significant effect on the shear bond strength of the composite to dentin over time. 


\section{MATERIALS AND METHODS}

TABLE (1): Materials used in the study, their descriptions and manufacturers.

\begin{tabular}{|c|c|c|}
\hline Material & Description & Manufacturer \\
\hline \multirow{3}{*}{ Meta Etchant } & Acid etching gel & \multirow{3}{*}{ Metabiomed Co.LTD. } \\
\hline & $37 \%$ Phosphoric & \\
\hline & Acid semi gel & \\
\hline \multirow{6}{*}{ Vertise Flow } & Self adhesive flowable composite. & \multirow{6}{*}{$\begin{array}{l}\text { Kerr (Kerr Orange, CA, } \\
\text { USA) }\end{array}$} \\
\hline & Matrix: GPDM adhesive monomer. & \\
\hline & Filler: prepolymerized fillers $20 \mu$, barium glass & \\
\hline & fillers $1 \mu$, nano-sized colloidal silica fillers $10-40 \mathrm{~nm}$, & \\
\hline & nano-sized Ytterbium fluoride fillers 40nm. Filler & \\
\hline & content: $70 \%$ wt & \\
\hline \multirow{5}{*}{ Proanthocyanidin } & - $\quad$ Powder & \multirow{5}{*}{$\begin{array}{l}\text { Sigma- Aldrich St. Louis, } \\
\text { MO, USA. }\end{array}$} \\
\hline & - $\quad \mathrm{C} 31 \mathrm{H} 28 \mathrm{O} 12$ & \\
\hline & - $\quad$ Molecular Weight: $136.30 \mathrm{~g} / \mathrm{mol}$ & \\
\hline & - $\quad$ Mean particle size: $2 \mu \mathrm{m}$ & \\
\hline & - Soluble in ethanol & \\
\hline \multirow{5}{*}{ Quercetin } & - $\quad$ Powder & \multirow{5}{*}{$\begin{array}{l}\text { Sigma- Aldrich St. Louis, } \\
\text { MO, USA. }\end{array}$} \\
\hline & - $\mathrm{C}_{15} \mathrm{H}_{10} \mathrm{O}_{7}$ & \\
\hline & - Molecular Weight: $302.24 \mathrm{~g} / \mathrm{mol}$ & \\
\hline & - $\quad$ Mean particle size: $2 \mu \mathrm{m}$ & \\
\hline & - Soluble in ethanol & \\
\hline \multirow{5}{*}{ Chlorogenic acid } & - $\quad$ Powder & \multirow{5}{*}{$\begin{array}{l}\text { Sigma- Aldrich St. Louis, } \\
\text { MO, USA. }\end{array}$} \\
\hline & - $\quad \mathrm{C}_{16} \mathrm{H}_{18} \mathrm{O}_{9}$ & \\
\hline & - Molecular Weight: $354.31 \mathrm{~g} / \mathrm{mol}$ & \\
\hline & - $\quad$ Mean particle size: $2 \mu \mathrm{m}$ & \\
\hline & - Soluble in ethanol & \\
\hline \multirow{5}{*}{ Hesperidin } & - $\quad$ Powder & \multirow{5}{*}{$\begin{array}{l}\text { Sigma- Aldrich St. Louis, } \\
\text { MO, USA. }\end{array}$} \\
\hline & - $\mathrm{C}_{28} \mathrm{H}_{34} \mathrm{O}_{15}$ & \\
\hline & - Molecular Weight: $610.56 \mathrm{~g} / \mathrm{mol}$ & \\
\hline & - $\quad$ Mean particle size: $2 \mu \mathrm{m}$ & \\
\hline & - Soluble in ethanol & \\
\hline
\end{tabular}

\section{Sample size calculation}

Sample size calculation was done at $90 \%$ power and 95\% confidence interval. For shear bond strength testing; 12 specimens for each group were required, however the number of specimens used in the study was increased to 20 specimens for each group to attain more reliable bond strength results. To assess the shear bond strength of Vertise flow flowable composite to human dentin at 24 hours; a total of 100 specimens were needed $(n=20$ for each group). To assess the shear bond strength after aging by thermocycling, as well as analyzing the failure mode; a total of 100 specimens were needed ( $n=20$ for each group). For SEM investigation of the composite resin/ dentin interface, a total of 15 specimens were examined ( $\mathrm{n}=3$ for each group). 
The total number of specimens for this in-vitro study was 215 specimens. The total number of molars used in the study was 115 , since each molar gave rise to two specimens for the shear bond strength testing.

\section{Preparation of the pre- treatment solutions}

In order to obtain a solution of concentration of $2 \%{ }^{(15)}$ of each pre- treatment material; $2 \mathrm{~g}$ of powder of each of the indicated material were added to $100 \mathrm{ml}$ absolute ethanol (99\%) in transparent glass bottles. Weighing of powder was done using a four digits sensitive balance (Sartorious AZ 214, Sartorious Mechatronics Corp, USA).

Mixing of powder and ethanol was done ultrasonically using Hielscher ultrasonic homogenizer (200 W, UP200St, Germany) for 30 seconds intervals; till obtaining homogenous one phase solutions. ${ }^{(17)}$

To ensure that the obtained solutions were homogenous; a sample from each solution was passed by a filter paper (Sterlitech membrane filter, $0.02 \mu \mathrm{m})$, then the upper surafce of the filter paper was examined by an enlarging lense and with the aid of an excavator to detect any remaining precipitates if found.

\section{Specimens' grouping and preparation of experi- mental composite}

Specimens were divided into five groups according to the following:

Group I: Dentin was etched and Vertise Flow flowable self adhesive composite was applied without any pre- treatment. This was considered the control group.

Group II: Etched dentin was pre-treated with $2 \%$ proanthocyanidin solution prior to application of Vertise Flow flowable self adhesive composite.

Group III: Etched dentin was pre- treated with $2 \%$ quercetin solution prior to application of Vertise Flow flowable self adhesive composite.
Group IV: Etched dentin was pre- treated with $2 \%$ chlorogenic acid solution prior to application of Vertise Flow flowable self adhesive composite.

Group V: Etched dentin was pre- treated with $2 \%$ hesperidin solution prior to application of Vertise Flow flowable self adhesive composite.

\section{Evaluation of shear bond strength (SBS) of Ver- tise flow flowable composite to human dentin.}

\section{a) Teeth selection and specimens' preparation}

A total of one hundred (100), freshly extracted, sound human permanent molars were collected in order to prepare 200 specimens. Teeth were extracted for periodontal reasons within the age group of 50-70 years (Oral surgery department, Faculty of Dentistry, Ain- Shams University). Only teeth with no cracks, restorations, or developmental anomalies were selected. Scaling and polishing were performed to remove any remaining calculus. Teeth were then randomly divided into five groups; so that each group included 20 molars and stored in thymol solution $(0.025 \%)$ at room temperature for a maximum of 2 weeks before being used.

\section{b) Teeth cutting}

For each molar, roots at the cemento- enamel junction (CEJ) were removed using an Isomet linear precision saw (Buehler 4000, Ltda., Lake Bluff, USA), at a low speed, under copious water spraying. A flat dentin surface was then obtained by using a water-cooled orthodontic model-trimmer that was used to remove enamel and flatten the occlusal surface of each tooth. Then, a midpoint along the crown length between the flat occlusal surface and CEJ was determined using digital calliper (CD6'CS Mitutoyo, Japan). Half of the crown height was then removed to expose mid-coronal dentin. This step was done under copious air/ water coolant spray using an Isomet linear precision saw, at a blade speed of $1600 \mathrm{rpm}$. 
Each prepared tooth was embedded in chemical cured acrylic resin placed in a plastic mold, with its long axis perpendicular to the base of the acrylic block. To obtain dentin surface flushing with the acrylic resin holding block, the flat dentin surface was placed on a glass slap facing down. Then, the mold was placed around it followed by pouring chemical cured acrylic resin in it.

A 150 , followed by 350 grit silicon-carbide papers (Buehler, USA) were used to grind the dentin surface flat and perpendicular to the tooth longitudinal axis. A 600 grit silicon- carbide paper was used for 1 minute with water coolant for finishing of the surface and to create a standardized smear layer.

All specimens were ultrasonically cleaned to ensure absence of any debris on their surfaces. ${ }^{(18)}$

To maintain hydration, dentin specimens were placed in a tray containing water and stored in an incubator (Titanox, ART.A3213-400I, Italy) at $37^{\circ} \mathrm{C}$ for 24 hours before bonding. ${ }^{(19)}$

\section{c) Dentin conditioning (acid etching)}

Dentin surfaces of all specimens were etched with $37 \%$ phosphoric acid solution for 15 seconds, rinsed thoroughly with distilled water. Excess water was then gently blot-dried; with absorbent paper pads, leaving the surface visibly moist. ${ }^{(20)}$

\section{d) Pre-treating the etched dentin surface}

Subsequent to the etching step, specimens were treated with the indicated solutions, prior to composite application. Twenty molars were needed for each group (40 specimens). The control group specimens were left untreated after being etched. To standardize the amount of the applied pre- treating solutions on dentin; $0.3 \mathrm{ml}$ of the prepared solution was aspirated using an insulin syringe $(0.3 \mathrm{ml})$ and dropped on dentin surface. The solution was then distributed on dentin surface using a small brush with minimal pressure. The solution was gently dried with air stream for 5 seconds to ensure excess solvent evaporation.

\section{e) Application of composite}

On the flat dentin surface of each molar, two polyethylene tubes (Ultramed, SAE, size: 8 FG; $2 \mathrm{~mm}$ in height, with an internal diameter of $2 \mathrm{~mm}$ ) were placed; leaving a distance of approximately $2 \mathrm{~mm}$ between them. The first tube was placed on the flat dentin surface and supported in place by a probe and aided lightly by fingers. An initial layer (approximately $0.5 \mathrm{~mm}$ thickness) of flowable resin composite was dispensed into the tube. The composite was polymerized for 20 seconds, according to manufacturer instructions, using an LED curing unit (Elipar Free Light II; 3M/ ESPE, St. Paul, MN, USA; light intensity: $1,000 \mathrm{~mW} / \mathrm{cm} 2$ ). This initial layer helped to support the polyethylene tube in place. Additional composite was then injected to fill the tube. The surface layer was covered with a celluloid matrix and a glass slide on top. Then light curing was done for 20 seconds. The second tube was also placed on the dentin surface, approximately $2 \mathrm{~mm}$ away from the first one, and composite was injected in the tube in the same way to obtain two composite specimens bonded to the flat dentin surface of each tooth (fig.1). After completion of composite curing, the tubes were removed carefully using a sharp scalpel. Specimens were examined for any defects or undesirable excess material under a light stereomicroscope at X10 magnification. ${ }^{(19)}$ Any specimens with defects were discarded.

All specimens were then stored in distilled water at $37^{\circ} \mathrm{C}$ for 24 hours in an incubator. Twenty specimens for each group were tested for shear bond strength of Vertise Flow composite to dentin at 24 hours storage. Other 20 specimens in each group were subjected to thermocycling before being tested for the shear bond strength. 


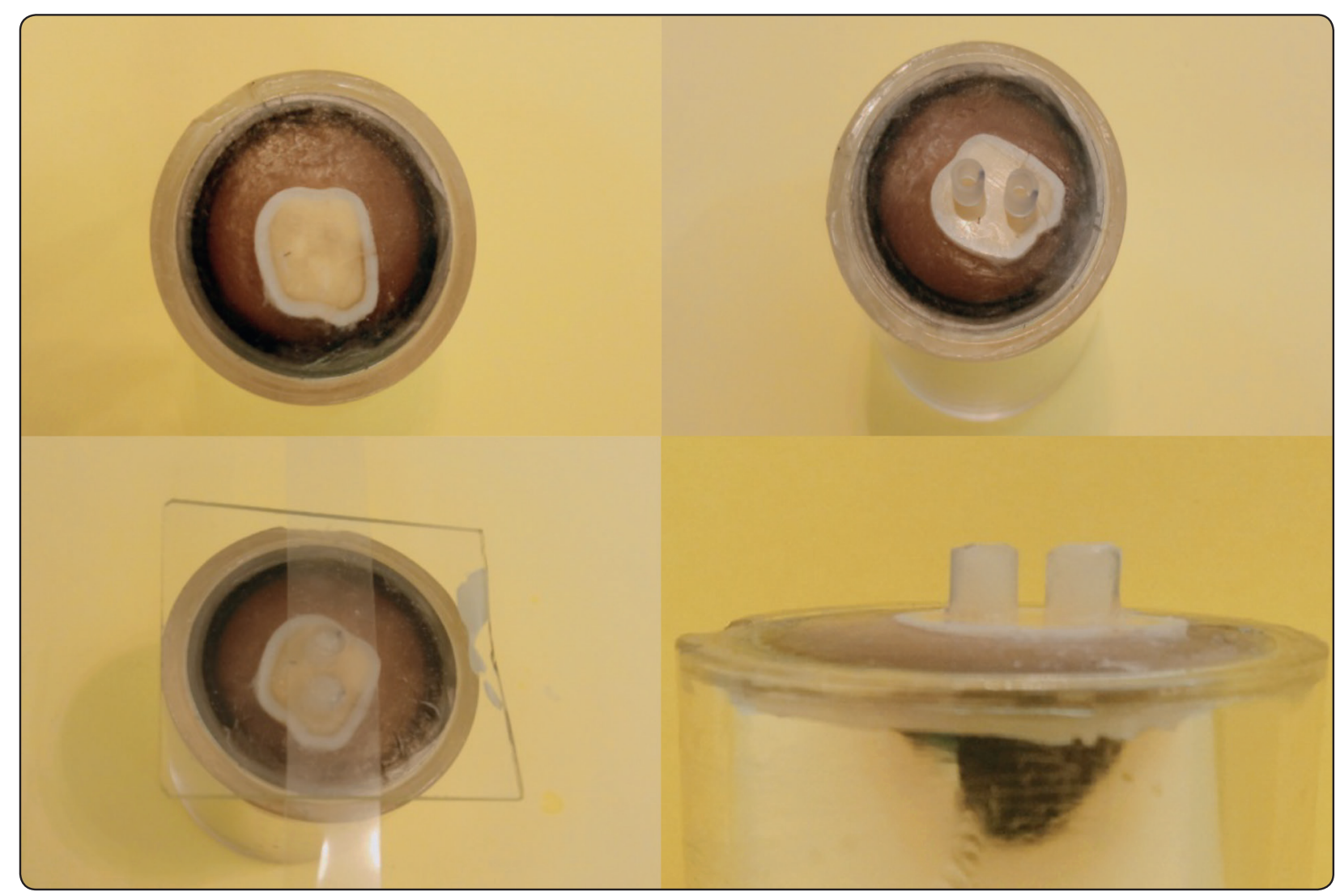

Fig. (1): Steps of preparation of specimens for shear bond strength testing: two Vertise Flow composite resin specimens bonded to the flat dentin surface.

\section{f) Aging by thermocycling}

As an aging protocol; thermocyling of specimens was done between $5^{\circ} \mathrm{C}$ and $55^{\circ} \mathrm{C}$ for 5,000 cycles using a thermocycler (Thermoscientific 1100, Mechatronic $\mathrm{GmbH}$, Germany), with a dwell time of 30 seconds and a transfer time of 5 seconds between each bath. ${ }^{(21)}$ After that, shear bond strength testing for the aged specimens was performed.

\section{g) Shear bond strength testing}

Specimens were secured in the holder of a universal testing machine (Instron Instruments 3365, USA, with a load cell of $5 \mathrm{kN}$ ). Each specimen was oriented so that shear load was directed parallel to the bonded interface through a knife- edge blade at cross head of speed $0.5 \mathrm{~mm} / \mathrm{min}$ until failure occurs. The load at failure was recorded in Newton $(\mathrm{N})$. Shear bond strength (SBS) was then calculated in
mega-Pascal (MPa) by dividing the failure load in Newtons (N) by the bonded surface area (in $\mathrm{mm}^{2}$ ). (19) A total of 200 specimens were tested, $n=40$ for each group; 20 specimens measured at 24 hours and 20 specimens measured after thermocycling.

\section{II- Failure mode assessment.}

Assessment of failure mode was done for the specimens subjected to aging by thermocycling, after being tested for SBS. The assessment was performed by detecting the Adhesive Remnant Index Scoring in each group, as well as by identifying the failure mode: either adhesive, mixed or cohesive.

\section{A. Failure analysis through Adhesive Remnant Index Scoring (ARI):}

The dentin surface of each specimen was microscopically observed and its debonded resin 
composite counterpart was analyzed. A digital microscope (Olympus - Japan) at a magnification $30 \mathrm{X}$ was used to analyze the fracture pattern at the fractured interface. A total of 100 specimens were examined, $\mathrm{n}=20$ for each group.

Each specimen was given a score according to the (ARI) ${ }^{(22)}$ with a score scale from 0 to 3 . An image analysis soft ware (Olympus cell B, Version 3.3) was used to record the specimens' scores. As the ARI score increases, as this indicates better bonding performance:

- Score 0: No composite is left on dentin surface.

- Score 1: Less than half of the dentin surface is covered with composite.

- Score 2: More than half of the dentin surface is covered with composite.

- Score 3: The whole dentin surface is covered with composite.

The frequency distribution of ARI scores among the tested groups was then statistically analyzed.

\section{B) Failure mode of the composite/ dentin adhesive junction:}

Failure mode was identified according to the following:

- Adhesive failure in case of specimens recorded score 0

- Mixed failure in case of specimens recorded scores 1 and 2

- Cohesive failure in composite in case of specimens recorded score 3

III- Assessment of Vertise flow composite resin / dentin junction (hybrid layer) by scanning electron microscope (SEM).

\section{a) Specimens' preparation}

Scanning electron microscopic imaging was performed to evaluate the hybrid layer. A total of 15 premolars were used ( $\mathrm{n}=3$ for each group). Roots of teeth were removed and mid-coronal dentin was exposed using an Isomet linear precision saw under air/ water coolant spray, working at a blade speed of $2600 \mathrm{rpm}$. All specimens were polished with silicon- carbide papers under water, using sequentially 150, 350, 600 grit. Prepared teeth were allocated into the five groups ( $\mathrm{n}=3$ premolars for each group). Dentin conditioning and its treatment regimens were performed as previously described for shear bond strength testing. Vertise Flow flowable composite resin was applied in a thin layer (approximately 0.5 $\mathrm{mm}$ ) to the surface and distributed lightly using a micro-brush. Thinning was performed using the brush for 15 seconds with a minimal pressure, and then light cured for 20 seconds. A second layer of the flowable composite was applied on the previous layer, in thickness of approximately $0.5 \mathrm{~mm}$ and also light cured for 20 seconds. ${ }^{(23)}$

\section{b) Thermocycling}

Simulating the thermal changes occurring in the oral cavity, specimens were subjected to thermocycling as mentioned before in section (I.f.). After that, assessment of the adhesive junction was carried out. ${ }^{(21)}$

\section{c) Teeth cutting and composite resin/ dentin inter- face revelation}

To expose the composite/ dentin adhesive junction for SEM investigation; teeth were sectioned using an Isomet linear precision saw, under air/ water coolant spray. Sectioning was performed through the composite resin/dentin interface longitudinally, in a bucco- lingual direction, perpendicular to the bonded surface. ${ }^{(24)}$

Then, the bonded interfaces were polished and smoothed with silicon carbide paper sequentially $320,600,1000$, and 1200 grit under water. The specimens were then cleaned with $37 \%$ phosphoric acid for five seconds, rinsed in water for 30 seconds. Etching step was performed to remove the polishing smear layer and any minerals within the hybrid layer that were not protected by resin infiltration. ${ }^{(25,26)}$ 
In order to dissolve all collagen exposed beneath the hybrid layer, specimens were submerged in $5 \%$ sodium hypochlorite $(\mathrm{NaOCl})$ for ten minutes and rinsed for five minutes, then left to dry. ${ }^{(26)}$

\section{d) Scanning electron microscopic (SEM) examination}

Specimens were mounted on aluminum tubs. Gold sputtering was performed, using a gold sputter coater (SPI Module, USA). Enamel surfaces were then observed under scanning electron microscope (JSM 5500 LV, JEOL Ltd, Japan) at a magnification of $3000 X$.

\section{Statistical analysis}

Categorical data were presented as frequency and percentage values and were analyzed using Fisher's exact test followed by pair- wise comparisons utilizing multiple z-tests with Bonferroni correction. Numerical data were presented as mean and standard deviation (SD) values. Shapiro-Wilk's test was used to test for normality. Homogeneity of variances was tested using Levene's test. Data were parametric and showed variance homogene- ity so one-way ANOVA test followed by Tukey's post hoc test was used to analyze intergroup comparisons. The significance level was set at $\mathrm{p}<0.05$ within all tests. Statistical analysis was performed with R statistical analysis software version 4.1.1 for Windows. R Core Team (2021).

\section{RESULTS}

\section{I- Results of shear bond strength testing}

Descriptive statistics for shear bond strength values were presented in table (2). Means and standard deviations (SD) of shear bond strength values (SBS) among different groups (intergroup comparisons) were presented in table (3) and figure (2). At 24 hours measuring, there was no statistical significant difference between the tested groups $(\mathrm{p}=0.933)$. The mean shear bond strength value for group I (control) was $(29.95 \pm 1.92 \mathrm{MPa})$. Group II (proanthocyanidin) measured $(30.32 \pm 1.88 \mathrm{MPa})$. Group III (quercetin) measured (30.44 $\pm 1.87 \mathrm{MPa})$. Group IV (Chlorogenic acid) measured $(30.46 \pm 2.17 \mathrm{MPa})$. Group V (Hesperidin) measured (30.28 $\pm 2.22 \mathrm{MPa})$.

TABLE (2): Descriptive statistics for shear bond strength values (MPa) among different groups at 24 hours and after thermocycling.

\begin{tabular}{|c|c|c|c|c|c|c|c|}
\hline \multirow{2}{*}{ Measurement } & \multirow{2}{*}{ Treatment } & \multirow{2}{*}{ Mean } & \multicolumn{2}{|c|}{$95 \%$ CI } & \multirow{2}{*}{ SD } & \multirow{2}{*}{ Median } & \multirow{2}{*}{ IQR } \\
\hline & & & Lower & Upper & & & \\
\hline \multirow{5}{*}{ At 24 hours } & Group I : Control & 29.95 & 29.11 & 30.79 & 1.92 & 30.22 & 2.78 \\
\hline & Group II : Proanthocyanidin & 30.32 & 29.50 & 31.15 & 1.88 & 30.55 & 3.02 \\
\hline & Group III : Quercetin & 30.44 & 29.63 & 31.26 & 1.87 & 30.69 & 2.31 \\
\hline & Group IV : Chlorogenic acid & 30.46 & 29.51 & 31.41 & 2.17 & 30.90 & 2.80 \\
\hline & Group V : Hesperidin & 30.28 & 29.31 & 31.25 & 2.22 & 30.23 & 3.64 \\
\hline \multirow{5}{*}{$\begin{array}{c}\text { After } \\
\text { thermocycling }\end{array}$} & Group I : Control & 18.87 & 18.40 & 19.34 & 1.08 & 18.78 & 1.50 \\
\hline & Group II : Proanthocyanidin & 30.12 & 29.71 & 30.53 & 0.93 & 30.15 & 1.42 \\
\hline & Group III : Quercetin & 25.89 & 25.64 & 26.15 & 0.58 & 25.91 & 0.73 \\
\hline & Group IV : Chlorogenic acid & 12.36 & 12.00 & 12.73 & 0.83 & 12.30 & 0.98 \\
\hline & Group V : Hesperidin & 25.76 & 25.43 & 26.09 & 0.76 & 25.78 & 1.09 \\
\hline
\end{tabular}

$95 \% C I=95 \%$ confidence interval for the mean; $S D=$ standard deviation; $I Q R=$ interquartile range 
After thermocycling the statistical analysis of shear bond strength data showed a significant difference in SBS values between different group $(\mathrm{p}<0.001)$. Post hoc pair-wise comparisons at $(\mathrm{p}<0.001)$ revealed that group II (proanthocyanidin) recorded the highest SBS $(30.12 \pm 0.93 \mathrm{MPa})$ among all groups. Whereas, group III (quercetin) and group V (hesperidin) recorded lower SBS values $(25.89 \pm 0.58 \mathrm{MPa}$ and $25.76 \pm 0.76 \mathrm{MPa})$ respectively; with no statistically significant difference between them. Following that, group I (control) recorded lower SBS value $(18.87 \pm 1.08 \mathrm{MPa})$. Finally, group IV (chlorogenic acid) recorded the least SBS value (12.36 $\pm 0.83 \mathrm{MPa})$ compared to all groups.

\section{Statistical correlation between shear bond} strength values of different groups at $\mathbf{2 4}$ hours and after thermocycling

Statistical comparison of shear bond strength mean values of different groups at 24 hours to that after thermocycling were presented in table (3) and figure (3). Group II (Proanthocyanidin) revealed no significant difference between the value measured after thermocyling and that measured at 24 hours ( $\mathrm{p}=0.668$ ). While for other groups; values measured after 24 hours storage were significantly higher than those measured after thermocycling $(\mathrm{p}<0.001)$.

\section{II- Results of failure mode assessment}

\section{A) Results of frequency distribution of ARI scores for different groups}

Results of intergroup comparison of ARI scores distribution were shown in table (4). A significant difference in ARI scores distribution was observed between different groups $(\mathrm{p}<0.001)$. Majority of specimens of group I (control) and group IV (chlorogenic acid) had recorded score (1) [12:(60.0\%) for both groups], and no significant difference was observed between all groups concerning score (1) records. Concerning group II (proanthocyanidin), group III (quercetin) and group $\mathrm{V}$ (hesperidin), the majority of specimens had registered score (2) [14:(70.0\%), 12:(60.0\%) and 11:(55.0\%) respectively] with no statistical difference between them. Post hoc pair-wise comparisons showed that group IV (chlorogenic acid) revealed a significantly higher percentage of specimens with score (0) than other groups; except the control group $(\mathrm{p}<0.001)$, but it showed significantly lower percentage of specimens having score (2) when compared to other groups; except the control group $(\mathrm{p}<0.001)$. Comparing group IV to the control group revealed comparable results concerning all scores. Additionally, all groups showed no statistically significant difference between them concerning score (3) records.

TABLE (3): Means and standard deviations (SD) of shear bond strength values in (MPa) among different groups after at 24 hours and after thermocycling (An Intergroup comparison).

\begin{tabular}{ccccccc}
\hline \multirow{2}{*}{\begin{tabular}{c} 
Measurement \\
\cline { 2 - 6 }
\end{tabular}} & $\begin{array}{c}\text { Group I } \\
\text { Control }\end{array}$ & $\begin{array}{c}\text { Group II } \\
\text { Proanthocyanidin }\end{array}$ & $\begin{array}{c}\text { Group III } \\
\text { Quercetin }\end{array}$ & $\begin{array}{c}\text { Group IV } \\
\text { Chlorogenic acid }\end{array}$ & $\begin{array}{c}\text { Group V } \\
\text { Hesperidin }\end{array}$ & p-value \\
\hline At 2 4 hours & $29.95 \pm 1.92^{\mathrm{A}}$ & $30.32 \pm 1.88^{\mathrm{A}}$ & $30.44 \pm 1.87^{\mathrm{A}}$ & $30.46 \pm 2.17^{\mathrm{A}}$ & $30.28 \pm 2.22^{\mathrm{A}}$ & $\mathbf{0 . 9 3 3}$ \\
$\begin{array}{c}\text { After } \\
\text { thermocycling }\end{array}$ & $18.87 \pm 1.08^{\mathrm{C}}$ & $30.12 \pm 0.93^{\mathrm{A}}$ & $25.89 \pm 0.58^{\mathrm{B}}$ & $12.36 \pm 0.83^{\mathrm{D}}$ & $25.76 \pm 0.76^{\mathrm{B}}$ & $<\mathbf{0 . 0 0 1 *}$ \\
\hline p-value & $<\mathbf{0 . 0 0 1 *}$ & $\mathbf{0 . 6 6 8}$ & $<\mathbf{0 . 0 0 1 *}$ & $<\mathbf{0 . 0 0 1 *}$ & $<\mathbf{0 . 0 0 1 *}$ \\
\hline
\end{tabular}

Different superscript letters indicate a statistically significant difference within the same horizontal row. 


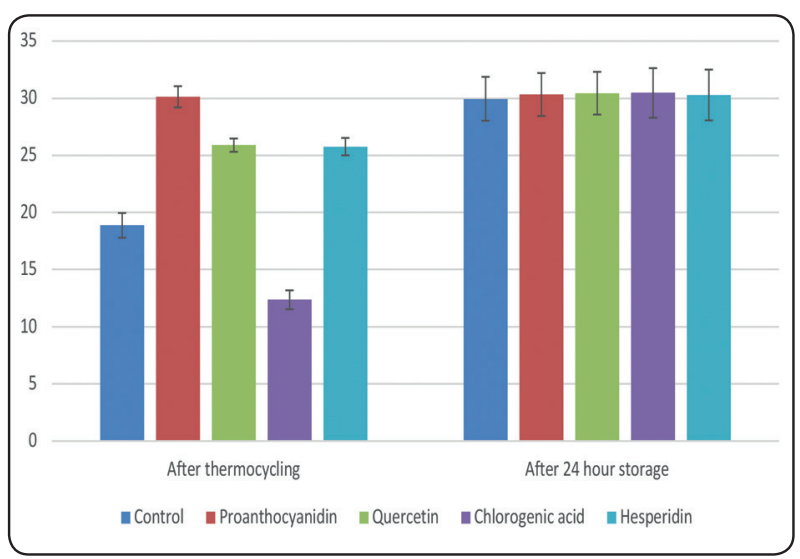

Fig. (2): Bar chart showing means and standard deviations of shear bond strength values (MPa) of different groups at 24 hours and after thermocycling.

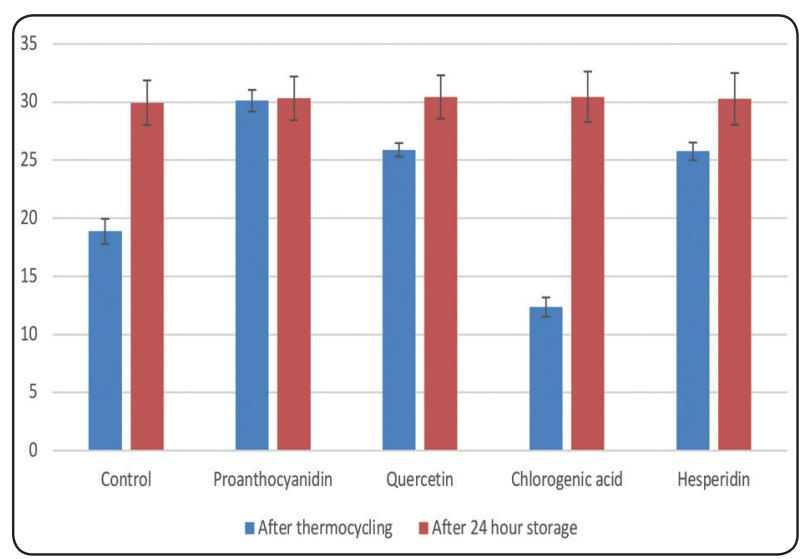

Fig. (3): Bar chart showing means and standard deviations of shear bond strength values (MPa) in different groups at 24 hours compared to those after thermocycling.

Table (4): Frequency distribution of ARI scores for different groups (An intergroup comparison)

\begin{tabular}{|c|c|c|c|c|c|c|c|}
\hline \multicolumn{2}{|c|}{$A R I$} & $\begin{array}{c}\text { Group I } \\
\text { (Control) }\end{array}$ & $\begin{array}{c}\text { Group II } \\
\text { (Proanthocyanidin) }\end{array}$ & $\begin{array}{c}\text { Group III } \\
\text { (Quercetin) }\end{array}$ & $\begin{array}{l}\text { Group IV } \\
\text { (Chlorogenic }\end{array}$ & $\begin{array}{c}\text { Group V } \\
\text { (Hesperidin) }\end{array}$ & \multirow{2}{*}{ p-value } \\
\hline \multirow{2}{*}{$\begin{array}{l}\text { Score } \\
(0)\end{array}$} & $\mathbf{n}$ & $5^{\mathrm{AB}}$ & $0^{\mathrm{B}}$ & $0^{\mathrm{B}}$ & $8^{\mathrm{A}}$ & $0^{\mathrm{B}}$ & \\
\hline & $\%$ & $25.0 \%$ & $0.0 \%$ & $0.0 \%$ & $40.0 \%$ & $0.0 \%$ & \multirow{7}{*}{$<0.001 *$} \\
\hline \multirow{2}{*}{$\begin{array}{l}\text { Score } \\
\text { (1) }\end{array}$} & $\mathrm{n}$ & $12^{\mathrm{A}}$ & $4^{\mathrm{A}}$ & $8^{\mathrm{A}}$ & $12^{\mathrm{A}}$ & $9^{\mathrm{A}}$ & \\
\hline & $\%$ & $60.0 \%$ & $20.0 \%$ & $40.0 \%$ & $60.0 \%$ & $45.0 \%$ & \\
\hline \multirow{2}{*}{$\begin{array}{l}\text { Score } \\
\text { (2) }\end{array}$} & $\mathrm{n}$ & $3^{\mathrm{BC}}$ & $14^{\mathrm{A}}$ & $12^{\mathrm{A}}$ & $0^{\mathrm{c}}$ & $11^{\mathrm{AB}}$ & \\
\hline & $\%$ & $15.0 \%$ & $70.0 \%$ & $60.0 \%$ & $0.0 \%$ & $55.0 \%$ & \\
\hline \multirow{2}{*}{$\begin{array}{l}\text { Score } \\
\text { (3) }\end{array}$} & n & $0^{\mathrm{A}}$ & $2^{\mathrm{A}}$ & $0^{\mathrm{A}}$ & $0^{\mathrm{A}}$ & $0^{\mathrm{A}}$ & \\
\hline & $\%$ & $0.0 \%$ & $10.0 \%$ & $0.0 \%$ & $0.0 \%$ & $0.0 \%$ & \\
\hline
\end{tabular}

Different superscript letters indicate a statistically significant difference within the same horizontal row. *significant $(p<0.05)$

\section{B. Results of failure modes}

Results of intergroup comparison of failure modes among different groups were presented in table (5), showing that there was a significant difference in failure modes between different groups $(p<0.001)$. Majority of all groups' specimens had mixed mode of failure. Post hoc pair-wise comparisons showed that group IV (chlorogenic acid) revealed a significantly higher percentage of specimens with an adhesive failure mode when compared to other groups; except the control group that was statistically comparable to it $(\mathrm{p}<0.001)$. However, group IV showed percentage of specimens having mixed failure mode significantly lower than those of group III (quercetin) and group V (hesperidin) $(\mathrm{p}<0.001)$, and no significant difference if compared 
Table (5): Intergroup comparison of failure modes among different groups

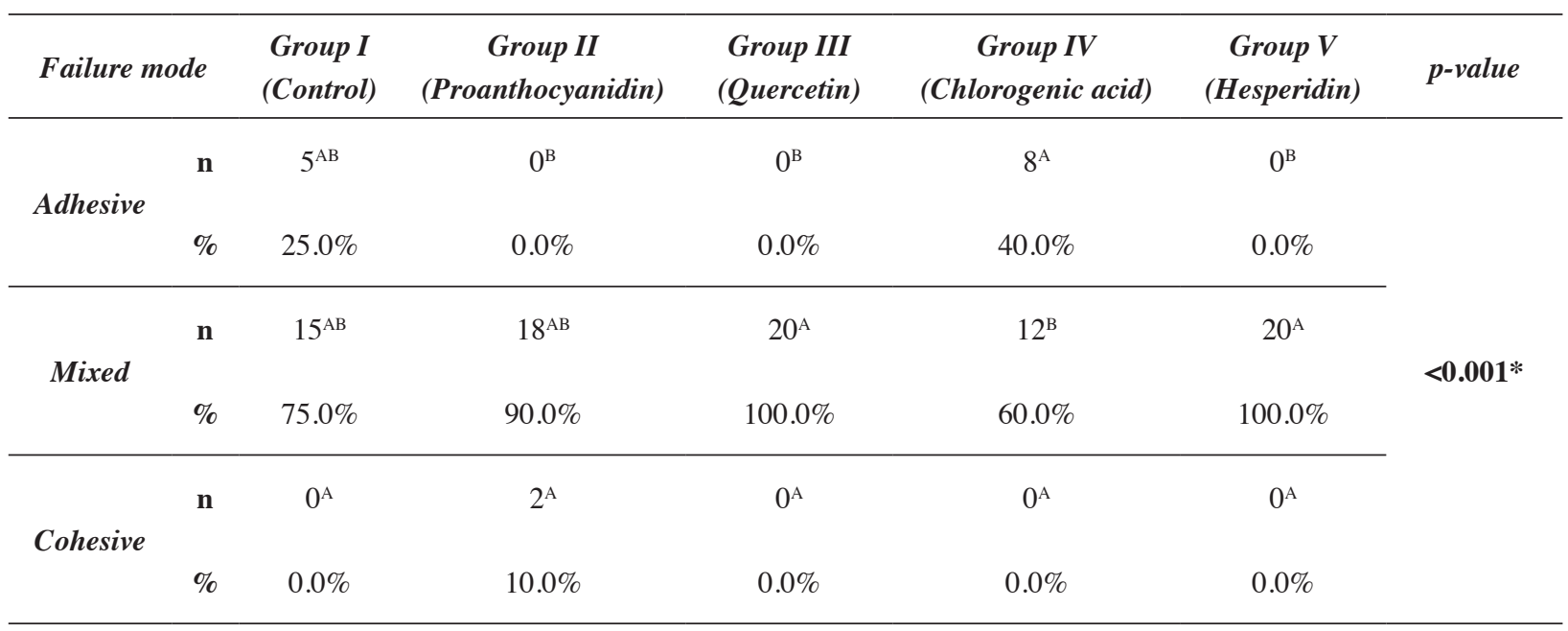

Different superscript letters indicate a statistically significant difference within the same horizontal row.

*significant $(p<0.05)$

to either group II (proanthocyanidin) or the control group. Concerning the cohesive mode of failure; no significant difference was observed between all tested groups, noticing that group II was the only group that showed cohesive failure [2: $(10 \%)]$.

\section{III- Results of scanning electron microscopic investigation of the hybrid layer}

Scanning electron microscopic analysis of flowable composite/ dentin interface concerning group I revealed an ill distinct and discontinuous hybrid layer. A distinct zone of collagen fibrils degradation, accompanied with composite resin break down was clearly detected in the photomicrograph fig.4a (yellow circle). The flowable composite showed superficial penetration into the demineralized dentin; as indicated by the very short resin tags.

Concerning group II, the SEM analysis represented by fig. $4 \mathrm{~b}$ revealed an intact continuous hybrid layer, with no gaps. The hybrid layer was thicker and more homogenous compared to the control group. The composite showed deeper penetration into the demineralized dentin compared to other experimental groups, as well as the control group. This was revealed by the relatively long resin tags characteristic for this group.

SEM analysis for group III (fig. 4c) showed a hybrid layer with little micro- porosities and minute areas of discontinuity that were less detected compared to those in the control group.

By observing SEM photomicrograph fig. 4d; group IV showed a discontinuous hybrid layer with short resin tags. Multiple micro- porosities and areas of discontinuity could be clearly detected along the whole dentin/ composite interface. Group IV possessed the most interrupted hybrid layer among all groups. Voids surrounding the resin tags were found at the deep zone of the hybrid layer (red arrows). In addition, areas of hydrolytic degradation of the hybrid layer were detected (blue arrows).

Concerning group V, the SEM analysis (fig. 4e) revealed a continuous hybrid layer, with minute gaps. The hybrid layer was more intact and more homogenous compared to the control group. 


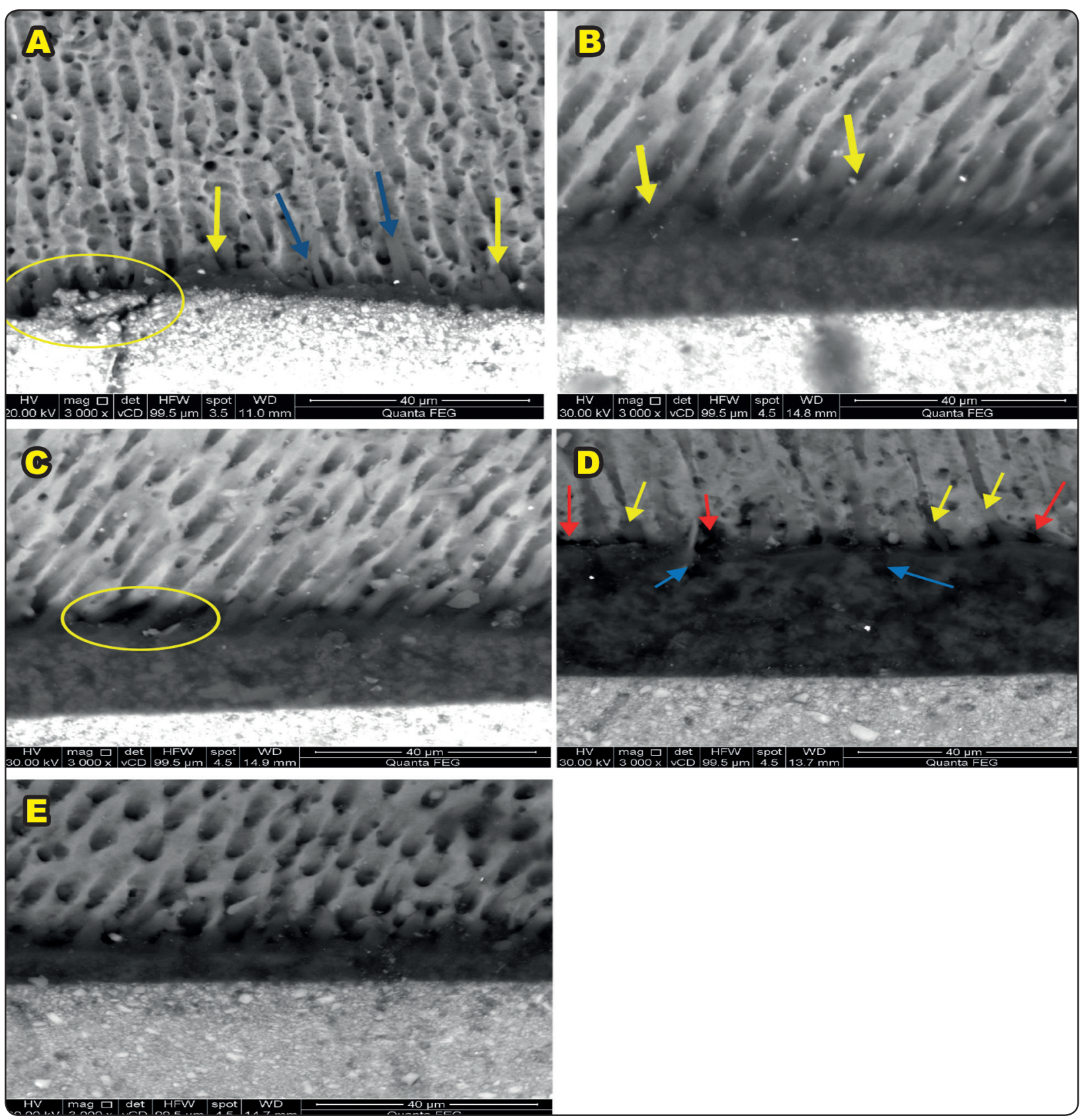

Fig. 4a: A scanning electron photomicrograph of group I (control); showing a very thin, ill distinct hybrid layer. Area of discontinuity (circle). Short resin tags (yellow arrows). Very few relatively longer resin tags (blue arrows).

Fig. 4b: A scanning electron photomicrograph of group II (Proanthocyanidin); showing a continuous thick hybrid layer, with no gaps. Long resin tags (yellow arrows).

Fig. 4c: A scanning electron photomicrograph of group III (Quercetin); showing a hybrid layer with few micro-porosities (circle).

Fig. 4d: A scanning electron photomicrograph of group IV (Chlorogenic acid); showing a discontinuous hybrid layer. Short resin tags (yellow arrows). Multiple micro- porosities (red arrows) and areas of discontinuity in the hybrid layer (blue arrows).

Fig. 4e: A scanning electron photomicrograph of group V(Hesperidin); showing a continuous hybrid layer, with minute gaps.

Fig. (4): Scanning electron photomicrographs for composite resin/ dentin interface for different groups. (3000X). 


\section{DISCUSSION}

The increasing attractiveness of tooth colored restorations had promoted research in the field of flowable composites that can be used as preventive resin restorations for minimally invasive occlusal class I, pit and fissure sealants, cavity liners, minimally invasive class II restorations and inner layer for class II posterior composite resin replacement in sealing the gingival margin to avoid deficiencies, class V lesions, bonding of orthodontic brackets and lingual orthodontic retainers.

Flowable composites have been reported to adapt well to the cavity walls, and appeared to have similar viscosity as the filled adhesives during application. Therefore, it was suggested to use flowable composites as a bonding agent to achieve a strong bonding at the restoration/tooth adhesive junction. Although there is not much noticeable difference between viscosity of filled adhesives and flowable composites during application; there seems to exist a border line of viscosity avoiding penetration into etched and primed dentin. Many studies clearly demonstrated that most of flowable composites are not capable of hybridizing etched and primed dentin as efficiently as the commercially available bonding agents. Previous microscopic investigation of dentin hybridization mechanisms showed that the viscosity of the flowable composites alone may not be the only crucial factor for their inferior bonding behavior. The chemical composition (presence of hydrophyllic adhesive promoters as HEMA), as well as filler size and fillers distribution are all considered contributing factors. Also, management of the surface energy of dentin is a prime factor. To keep a durable adhesive junction, it is important to improve cross linkages with collagen fibers and protect this hybridized resin/ collagen network against enzymatic or hydrolytic bio- degradation. ${ }^{(23)}$

Self-adhesive flowable composites (SAFCs) have been introduced as a new class of restorative material in adhesive dentistry. Vertise Flow and Fusio Liquid Dentin composites are widely available in the market. Their resin matrix contains acidic functional adhesive monomers mediating bonding with dental hard tissues, therefore separate etching and additional bonding are not required..$^{(7,27)}$

Concerning Vertise Flow; it includes glycerol phosphate dimethacrylate (GMPD) as a highly acidic functional monomer. In previous studies, Vertise Flow was shown to open the dentinal tubules and expose the micro-porous collagen fibrillar network. On the other hand, it was reported that for both Vertise Flow and Fusio Liquid Dentin, the removal of smear layer and creating micro-irregularities on the enamel surface are an advantageous goal that can be achieved by pre-etching the enamel surface. However, in a previous study (7) pre-etching of dentin by phosphoric acid was found to improve the sealing of Fusio Liquid Dentin but did not succeed to reduce leakage in dentin margins of Vertise Flow restorations. This may in part be ascribed to the wettability of Fusio Liquid Dentin due to its high flowability. In order to provide better adhesion, the resin should diffuse into the spaces between collagen fibers that were produced by the demineralization of hydroxyapatite during acid etching. It was previously mentioned that GPDM monomer used with Vertise Flow might probably etch rather than bond chemically to tooth structure. Self- adhering flowable composites should possess some chemical adhesion capacity as it cannot sufficiently penetrate deeply into dentin. Fusio Liquid Dentin seemed to be more profound than Vertise Flow in achieving this penetration after phosphoric acid etching; because of the 4- MET incorporated in it. ${ }^{(3,7)}$

Thus, Vertise Flow self adhering composite was the targeted composite resin to be concerned in the present study, and improving its bonding potential to demineralized dentin was the main point of the research.

It was previously claimed that micromechanical retention of SAFCs is inadequate because of their low etching capacity. The separate phosphoric acid etching step forms micro-retentive irregularities of 
the tooth structure. In the literature, considerable number of studies was conducted on the adhesion of self-adhesive resins. However, there are few studies on the bond strength or sealing ability of SAFCs. Poitvein et al. in $2013^{(3)}$ had reported that the bonding effectiveness of SAFCs (Vertise Flow and Fusio Liquid Dentin) was lower than that of the flowable composite used with etch-and rinse system in bur-cut dentin. For that reason, in the current study acid etching was performed prior to application of the treatment solutions.

Aging was considered an important step to be done in the current study; since water plays a pivotal role in the bond degradation. Water absorption results in plasticization of the dental adhesive with hydrolytic degradation, decreasing their physical properties and bond strength. The next consequence is resin elusion from hydrolytically unstable polymers within the hybrid layer. Collagen fibers become exposed to collagenolytic degradation as a result of being not fully enveloped by resin monomers. Finally, the dentin-resin bond is compromised..$^{(1,3)}$ SAFCs can uptake water and plasticize over time, as they include functional acidic monomers; that significantly increase the hydrophilicity of the resin. The acidic monomers may form spaces of partially demineralized, non-infiltrated zones of dentin that contain dissolved calcium and phosphate ions during self- etching. For that reason, thermocycling process was performed in the current study to induce hydrothermal aging, simulating the clinical conditions. Alternating temperatures between $5^{\circ} \mathrm{C}$ and $55^{\circ} \mathrm{C}$, coupled with the presence of water may increase the bond failure at the resin/dentin interface due to thermal stresses and water sorption. It was proposed that 10,000 cycles might represent approximately 1 year of in-vivo functioning, with 20 to 50 cycles considered equivalent to a single day. However, the International Standards Organization (ISO); in 1994 had considered a protocol of 500 cycles between water baths that were held at $5^{\circ} \mathrm{C}$ and $55^{\circ} \mathrm{C}$, with a dwell time in each bath for 20 to 30s was found appropriate in simulating the aging of biomaterials in the oral cavity. ${ }^{(28)}$ In the present study it was decided to perform thermal cycling to 5,000 cycles; that are equivalent to 6 months in- vivo service, and the results were statistically compared to the 24 hours shear bond strength. ${ }^{(29)}$

Several strategies were suggested by many authors to prevent degradation cascade of resin-dentin bonds. Among them was to increase the resistance of the exposed collagen fibrils to degradation by matrix metalloproteinases (MMPs), as they were reported to have the main role in degradation of demineralized collagen in the adhesive/dentin interface. For that reason, MMPs inhibitors had been concerned in the dental literature. Previous researches supposed two different mechanisms for matrix metalloproteinases inhibition; either by direct inhibition (inhibition of the collagenase enzyme release, binding to the zinc atom at the active center of the enzyme and thereby blocking its activity, or dislodging the enzyme from its receptors), or indirectly through silencing the enzyme effect by collagen cross-linking. Also, the antioxidant activity offered by many natural cross-linkers can help in stabilizing collagen and enhancing its synthesis.

Hence, the goal of this study was to try the application of natural MMPs, in a trial to enhance the adhesive quality and durability of Vertise Flow self adhesive flowable composite to dentin, with the introduction of new natural collagen cross- linkers and antioxidants to the field of adhesive dentistry.

A natural flavonoid was tried in the present study is proanthocyanidin. Proanthocyanidins are polymers consisting of catechin, epicatechin, epicatechin gallate and epigallocatechin units; that have been identified as potent collagenase inhibitors that posses an antioxidant property. Also, it is rich in proline that binds to collagen in a fast reaction rate. In addition, it can promote type I- collagen cross-linking by inducing hydrogen bonding between protein amide carbonyl and the phenolic hydroxyl. ${ }^{(30)}$ 
Another available cross- linking agent is quercetin. This natural compound- quercetin (3, $3^{\prime}, 4^{\prime}, 5,7$-pentahydroxyflavone), is a strong cytocompatible and highly polar flavonol antioxidant. It is positively charged with abundant hydroxyl $(\mathrm{OH})$ groups; therefore a number of interactions such as dispersion, dipole-dipole, hydrogen bonding and ionic interactions may occur between quercetin and the solvent, modifying the way this substance interacts with the collagen molecule. Similarly, the collagen conformation and isoelectric points of the amino acids may change in different solvents; thereby affecting their interactions with the crosslinking agent. Reorientation of the amino groups of collagen can occur depending on their proximity to the structure of the cross-linking agent. ${ }^{(31)}$

Chlorogenic acid; is a polyphenolic antioxidant; was also included in the study. Structurally, 5-caffeoylquinic acid is most predominant form of chlorogenic acid in plants. The antioxidant property of chlorogenic acid is attributed to its double bond conjugated catechol structure of the phenyl ring. ${ }^{(32)}$

Hesperidin is another available flavonoid of glycoside antioxidant, present in citrus fruits. The alleged action of this natural agent in protecting collagen against degradation is inhibition of MMPs and stabilization of the collagenous matrix. ${ }^{(33)}$

For dissolving the natural products used in the present study, ethanol was the best choice. Concerning proanthocyanidin; the stability of most cations was found to be high in either methanol or ethanol, and both were found to be more effective than water. Also, quercetin is soluble in ethanol for approximately $2 \mathrm{mg} / \mathrm{ml}$. In a previous study; ${ }^{(31)}$ ninhydrin assay showed that the degree of crosslinking in the quercetin dissolved in ethanol crosslinked scaffolds was higher than in the quercetin dissolved in other solvents scaffolds. Chlorogenic acid is soluble in ethanol for approximately $25 \mathrm{mg}$ / $\mathrm{ml}$. Finally, hesperidin is soluble in ethanol for approximately $1 \mathrm{mg} / \mathrm{ml}$. This information guided the choice of the solvent in the current study towards using ethanol.
In addition, ethanol wet-bonding protocol was found efficient to preserve the resin/dentin bond strength; as it involves removal of water from intra-fibrillar compartments, resulting in fibrillar shrinkage. This results in widening the inter-fibrillar spaces and permits more resin uptake. ${ }^{(34)}$ These data augmented the choice of ethanol as a solvent in the present study; in attempts to engage both benefits: the ethanol bonding strategy and the collagen crosslinking approach.

The concentration of the prepared pretreatment solutions was $2 \%$ wt. This concentration was decided based on previous researches that showed that increasing the antioxidant added to the resin adhesive more than $2 \%$ wt may deteriorate the bond strength. ${ }^{(15)}$

Ultrasonification was performed to promote an effective and fast dissolution of powder in liquid, to obtain a homogenous one- phase mixture. ${ }^{(17)}$

In the present study; testing the shear bond strength was performed, and its results were correlated to the failure mode. This helps to figure out the mechanical bonding ability of composite resin to dentin on applying the natural experimental pretreatments. Also, morphological SEM investigation of the interfacial ultra structure was done to attain a full description of the adhesive junction.

Concerning the results of the current study, the null hypothesis was rejected, as the tested groups showed significant differences between them, and also when compared to the control group regarding the shear bond strength of Vertise Flow flowable composite to dentin after aging by thermocycling.

The highest shear bond strength was given by group II (proanthocyanidin), and this can be also apparent by the SEM investigation that demonstrated an intact continuous hybrid layer, with no gaps or discontinuities; as clearly obvious in fig. $4 \mathrm{~b}$; indicating its high resistance to hydrothermal degradation. The relatively long resin tags characteristic for this group can reflect the long term stability of the formed hybrid layer. 
The deep penetration ability of proanthocyanidin in dentin could be attributed to its low molecular weight and presence of monomeric catechins that can reflect its low viscosity. Besides, the presence of hydrophilic compounds, constituting three hydroxyl groups in its molecular chemical structure, can give it a strong penetration power in demineralized dentin, and so can help proanthocyanidin to achieve its desired goal for creating a strong cross-linking of collagen network. Same reasons augment its strong antioxidant activity; because the antioxidant components in proanthocyanidin are highly water soluble. ${ }^{(35)}$

The fast collagen cross-linking ability of proanthocyanidin can be related to its high content of proline. Structurally, the phenolic hydroxyl in proline can induce strong hydrogen bonding to protein amide carbonyl in type I- collagen in a fast reaction. And by studying the structural changes occurring in dentin after acid etching; it is obvious that bonding of adhesive resins takes place mainly to type I- collagen. Dentin lining the inner walls of tubules is termed intratubular or peritubular dentin. The matrix of peritubular dentin differs from that of intertubular dentin by having relatively fewer collagen fibrils and a higher proportion of minerals, and therefore is more quickly dissolved in acids. ${ }^{(36)}$ By preferentially removing peritubular dentin, the intertubular dentin (a type I collagen-rich structure) becomes the main structure for bonding. Thus, concerning proanthocyanidin, intertubular dentin can be considered a profoundly suitable structure for it to accomplish its collagen cross-linking activity.

The shear bond strength results, as well as the SEM assessment reflected the high resistance of resin/ dentin adhesive junction to hydrothermal degradation on applying proanthocyanidin, in spite of its high hydrophilicity. This is mostly derived from the fast and profound hydrogen bonding to type I- collagen; creating an intact and void free hybrid layer that is highly resistant to hydrothermal degradation. This was clearly obvious on comparing the shear bond strength of group II at 24 hours to that after thermal cycling, where no statistically significance difference was found. This result was in agreement with Carvalho et al. (2016) ${ }^{(37)}$ who reported that the addition of green tea extract (proanthocyanidin) in a $2 \%$ by weight increased the bond strength of etch and rinse adhesive system to dentin. Also, in a study conducted by EL- Baz \& Aboulenien in (2018) ${ }^{(38)}$; the bond strength remained stable after 6 months storage in water and showed no statistically difference after thermocycling for 5,000 cycles. Accordingly, they concluded that anthocyanidins in green tea was surprisingly able to reduce dentin biodegradability and enhance the bonding strength to dentin.

On observing the results of failure mode assessment, group II specimens recorded $0 \%$ score 0 , $20 \%$ score $1,70 \%$ score 2 , and $10 \%$ for score 3 . This reflects the strong adhesive junction achieved by application of proanthocyanidin. Mode of failure was mainly mixed $90 \%$, with $70 \%$ of the specimens had more than half of their dentin surface kept covered by composite (score 2). No adhesive failure was observed. On comparing the failure mode of group II to that of group I; the percentage of score (2) specimens were significantly higher in group II than group I. All other scores and failure modes showed statistically comparable results. Hence, the failure mode assessment, as well as SEM features of groups I and II can support the higher shear bond strength values obtained on proanthocyanidin application in comparison to the control group.

Proanthocyanidin was previously tried in the field of adhesive dentistry. A study was conducted in 2012 by Epasinghe et al. ${ }^{(39)}$ to test the addition of proanthocyanidin to dental adhesives in three ratios; $1,2,3 \% \mathrm{wt}$. The study concluded that its incorporation into dental adhesives has no effect on dentin bond strength up to $2 \%$. However, the $3 \%$ showed decreased strength. This result was contradicting to the results of the current study; and the difference could be inferred to using proanthocyanidin as an added ingredient incorporated into the dental adhesive, in the study 
conducted by Epasinghe et al. ${ }^{(39)}$ This might have affected the proanthocyanidin properties regarding the antioxidant releasing activity. However, in the present study proanthocyanidin was applied alone as a pretreatment solution on dentin.

Following group II, the shear bond strength results of group III (Quercetin) and group V (Hesperidin) were found significantly less. Considering that SBS values of both groups III and V revealed no significant difference.

From observing the molecular chemical structure of quercetin, it contains 5 hydroxyl groups that might reflect its powerful strong hydrophilicity, although it yielded decreased SBS than proanthocyanidin that contained 3 hydroxyl groups in its molecular structure. This can direct attention towards other causative factors affecting the release of antioxidants rather than the degree of hydrophilicity, like low solubility of the protected quercetin glucoside. This glycosylated structure quercetin-3-o- $\beta$ - glucoside is the main antioxidant component having high ability to scavenge free radicals. But this glycoside has great resistance to splitting, rendering the antioxidant release slow and weak. ${ }^{(31)}$ High Performance Liquid Chromatography (HPLC) performed to separate and quantify flavonols; had previously shown that antioxidant release of quercetin is weaker compared to proanthocyanidin. Also, another factor is the type of collagen that quercetin can bind to. Quercetin had lower degree of collagen cross-linking, the crystal packing forces of quercetin changed by dissolution in the solvent. As mentioned before, quercetin is positively charged with abundant hydroxyl groups, and a number of interactions may occur between quercetin and the solvent, dispersion, dipole- dipole, hydrogen bonding, ionic interactions, this modify the way the substance interaction with the collagen network, similarly the collagen conformation and iso-electric points of the amino-acids may change in the solvent; thereby affecting their interaction with the cross-linking agent. Results observed following quercetin cross-linking were probably due to the elicited dehydration/ hydration effect of the solvent resulting in reorientation of the collagen amino acids leading to a lower degree of cross-linking. If a low degree of cross-linking takes place, then it could be expected to have a weak adhesive junction. Thus, group III revealed significantly lower SBS values than group II.

SEM investigation of group III (fig. 4c) showed a hybrid layer with little micro- porosities. Most of resin tags were found relatively shorter than that observed in group II. These structural observations can support the shear bond strength results and clarify that quercetin could be considered less profound than proanthocyanidin as a cross-linking compound. The failure mode results revealed that the mode of failure in group III was $100 \%$ mixed, and no specimens registered score 3 (cohesive failure in composite). While group II; showed mixed failure of $90 \%$, and leaving $10 \%$ cohesive failure in composite registering score 3. Although the failure mode results of both groups were statistically comparable, yet they were not contradicting to the shear bond strength results.

Shear bond strength values of group V (hesperidin) were significantly less than group II (proanthocyanidin). This could be attributed to the higher molecular weight of hesperidin $(610.56 \mathrm{~g} / \mathrm{mol})$ compared to proanthocyanidin $(136.30 \mathrm{~g} / \mathrm{mol})$ about six times, so consequently can give rise to less penetration ability in demineralized dentin compared to proanthocyanidin. The short resin tags and minute gap formation observed in the SEM photomicrograph fig. 4e supported this explanation. Inadequate penetration of the hesperidin pretreatment solution might have resulted in insufficient collagen fiber cross-linking, giving rise to a weaker adhesive junction compared to group II, and subsequently formation of a hybrid layer that is more prone to hydrolysis and degradation. This can imply that hesperidin is weaker in achieving collagen cross-linking compared to proanthocyanidin. The failure mode results revealed that the mode of failure in group $\mathrm{V}$ was $100 \%$ mixed, and no specimens registered score 3 (cohesive failure in composite). While group II; 
showed mixed failure of $90 \%$, and leaving $10 \%$ cohesive failure in composite registering score 3. Although the failure mode results of both groups were statistically comparable, yet they were not contradicting to the shear bond strength results.

On comparing the molecular weight of hesperi$\operatorname{din}(610.56 \mathrm{~g} / \mathrm{mol})$ to that of quercetin $(302.24 \mathrm{~g} /$ $\mathrm{mol}$ ), it was found to be nearly the double. This difference in molecular weight might not be considered as effective as in case of comparing to proanthocyanidin. Also, by recognizing the molecular chemical structure of hesperidin; it contains more $\mathrm{OH}$ groups than quercetin. This might result in more hydrophilicity and thus easier antioxidants release, as the antioxidants in hesperidin are water soluble. This can conquer its double molecular weight compared to quercetin; and accordingly yielded comparable SBS results. Results of failure mode for groups III and V showed no significant difference between them, and were found to be in line with SBS results.

By studying the SEM features (fig. 4) of both groups III and V, and comparing them to group I (control), it was observed that application of either quercetin (group III) or hesperidin (group V) can produce a thicker and more intact hybrid layer, with less microporosities than in case of the control group. These observations can augment and clarify the higher shear bond strength values obtained for both groups III and V compared to the control group. Furthermore, data obtained from SEM analysis were in concurrence with results of failure mode assessment, since both groups III and V showed statistically higher percentage of specimens recording score (2) in comparison to the control group. Application of either quercetin or hesperidin gave rise to a mixed mode of failure, with the majority of specimens recorded score 2 . This indicated that even though a mixed mode of failure was observed in the three groups, nevertheless application of either quercetin or hesperidin pretreatments lead to more composite resin remained bonded to dentin. As a worthy information, these records reflect the ability of attaining a stronger adhesive junction of composite resin to dentin on applying either quercetin or hesperidin pretreatments than on using the flowable composite resin with no pretreatment.

Concerning results of group IV (chlorogenic acid); it revealed the least SBS values compared to all groups, even the control group. This result can show that chlorogenic acid might not be considered a profound antioxidant compound as expected. By studying the chemical nature of antioxidants constituents of chlorogenic acid, it was found that they are highly fatty soluble, and not water soluble. ${ }^{(40)}$ In view of that information, it could be logically accepted that chlorogenic acid did not induce the desired antioxidant effect, causing a long term deterioration of the bond strength. These findings could interpret the SEM features in (fig. 4d) that revealed a discontinuous hybrid layer with short resin tags. Multiple microporosities and areas of discontinuity could be clearly detected along the whole dentin/ composite interface. Group IV possessed the most interrupted hybrid layer among all groups. These features can reflect the high vulnerability of hybrid layer to hydrothermal degradation. Voids surrounding the resin tags were found, indicating the high risk of collagen degradation illustrated by this group. This hydrothermal degradation can be considered the reason for the weak bond strength of flowable composite to dentin after thermocycling, and also can explain the mode of failure seen in group IV. Adhesive failure (score 0) was registered in $40 \%$ of specimens, denoting a weak adhesive junction. And the rest of specimens showed mixed failure of score1, where most of the composite resin was debonded from the dentin surface. No specimens showed either score 2 or 3 .

By observing the SEM characteristics of the control group (fig. 4a); the majority of resin tags were found short. The short resin tags can be considered a reflection of an insufficient hybridization of Vertise Flow self adhesive flowable composite to 
dentin. The discontinuity of the hybrid layer can be considered a consequent result of hydrolytic degradation of collagen fibrils and breakdown of the hybrid layer, in addition to hydrolytic degradation of the composite resin.

On comparing the SBS values of each group at 24 hours to that after thermocycling; it could be noticed that despite the comparable SBS results obtained for the tested groups at 24 hours, the permanence and stability of the adhesive junction after aging was variably affected by the type of the pretreatment solution, concerning its molecular weight, hydrophilicity, antioxidant power, as well as its cross-linking activity. These findings were in agreement with the SEM observations accomplished by Bumrungruan and Sakoolnamarka in 2016 (41), showing that the plain application of Vertise Flow self adhesive composite to dentin resulted in a gap found at the resin/dentin interface, without formation of a distinct hybrid layer, and thus suggested that GPDM may not perform as effectively as expected on the long term service.

Briefly, by categorizing the natural substances tested in the study; proanthocyanidin can be considered a highly potent MMPs inhibitor and a fast collagen cross- linker that can enhance the long term bond strength of flowable composite to dentin, followed by quercetin and hesperidin. However, application of chlorogenic acid was found undesirable; as it induced a negative effect on the resin/ dentin adhesive quality.

It is important to consider the gap between laboratory investigations and the in-vivoperformance of adhesive dental materials. The present in-vitro study lacks some vital clinical perspectives; as simulating the $\mathrm{pH}$ fluctuations and the chemical enzymatic attacks that may cause degradation in the bonding interface. Moreover, the effect of pulpal pressure, as well as the cycling masticatory stresses should be considered in future researches. Clinical trials are recommended to acquire more practically relevant data for application of natural MMPs inhibitors in the field of adhesive dentistry.

The present study involved the direct application of natural MMPs inhibitors and antioxidants to dentin as a sole pretreatment step. However, this strategy increases the clinical application steps. If the natural substances could be incorporated into the flowable composite as a constituent component, this could give a double benefit of improving its adhesive quality, and decreasing the clinical steps. For that; developing and assessment of new adhesive products containing natural MMPs inhibitors and antioxidants can be a challenging aspect for further scientific and industrial researches.

\section{CONCLUSIONS}

Within the limitations of the present study, the following conclusions could be deduced:

1- Long term aging has a definite bond degrading effect.

2- Proanthocyanidin; as a proline containing natural flavonoid; can be considered a profoundly fast collagen cross-linker, capable of improving the long term bonding performance of self adhesive flowable composite to dentin.

3- Water soluble antioxidants (as in proanthocyanidin, quercetin and hesperidin) can enhance the bond strength of flowable composite to dentin. On the other hand, fat soluble antioxidants (as in chlorogenic acid) might deteriorate the composite/ dentin adhesive junction by time.

\section{Financial support and sponsorship: Nil.}

Conflicts of interest: There are no conflicts of interest.

Ethical approval: The Ethical Committee, Faculty of Dentistry, Ain Shams University on its meeting number (120) had exempted the research from review; as it is performed on collected extracted teeth. The research approval number is: FDASURec ER122120. 


\section{REFERENCES}

1. Tawfic HM, Niazy MA, El- Sharkawy DA. The effect of $\mathrm{Zn}$ - doped adhesive alone or combined with calcium phosphate nanoparticles on the integrity of the bonded resin- dentin interface. ADJ.2017;4(3):289-296.

2. El- Zeiny HM, Abdel- Fattah WM, Abd- Elmotie MA. Shear bond strength of self adhering flowable composite after preliminary acid etching of dentin. Dent J.2016;41: 318- 322.

3. Poitevin A, De Munck J, Van Ende A, Suyama Y, Mine A, Peumans M. Bonding effectiveness of self- adhesive composites to dentin and enamel. Dent Mater. 2013; 29:221- 230.

4. Fu J, Kakuda S, Pan F, Hoshika S, Ting S, Fukuoka A, et al. Bonding performance of a newly developed step-less allin-one system on dentin. Dent Mater J. 2013;32: 203-211.

5. Tuloglu N, Tunc ES, Ozer S, Bayrak S. Shear bond strength of self-adhering flowable composite on dentin with and without application of an adhesive system. J Appl Biomater Funct Mater. 2014;12(2): 97- 101.

6. Abo El Naga A, Yousef M, Ramadan R, Bahgat SF, Alshawwa L. Does the use of a novel self-adhesive flowable composite reduce nanoleakage? Clinic, Cosmet and Investigat Dent. 2015; 7: 55- 64.

7. Celik EU, Kucukyilmaz E, Savas S. Effect of different surface pre-treatment methods on the microleakage of two different self-adhesive composites in Class V cavities. Europ J of Paediatric Dent. 2015; 16(1): 33- 38.

8. Yusoff NM, Johari Y,1 Ab Rahman I, Mohamad D, Khamis MF, Zaihan Ariffin Z, Husein A. Physical and mechanical properties of flowable composite incorporated with nanohybrid silica synthesised from rice husk. J Mater Res Technol. 2019; 8(3): 2777- 2785.

9. Nivedita L, Prakash V, Mitthra S, Gold NS, Mary P, Venkatesh A, Subbiya A. Evaluation of the effect of the effect of collagen stabilizing agents like chitosan and proanthocyanidin on the shear bond strength to dentin and microleakage of resin composite at enamel and cemental walls: an in vitro study. J Conserv Dent.2019; 2: 483- 489.

10. Gotti VB, Feitosa VP, Sauro S, Correr-Sobrinho L, Leal FB, Stansbury JW, Correr AB. Effect of antioxidants on the dentin interface bond stability of adhesives exposed to hydrolytic degradation. J Adhes Dent. 2015; 17(1): 35- 44.

11. Yang H, Li K, Yan H, Liu S, Wang Y, Huang C. High-performance therapeutic quercetin-doped adhesive for adhesive-dentin interfaces. Scientific Reports.2017; 7(1):1- 11.
12. Szalewski L, Kaminska A, Wallner E, Batkowska J, Warda T, Wojcik D, Borowicz J. Degradation of a micro- hybrid dental composite reinforced with polyaramide fiber under the influence of cyclic loads. Appl Sci. 2020; 10(20): 72967309 .

13. Amorati R, Baschieri A, Cowden A, Valgimigli L. The antioxidant activity of quercetin in water solution. Biomimetics. 2017; 2 (3): 9- 22.

14. Naveed M, Hejazi V, Abbas M, Kamboh AA, Khan GJ, Shumzaid M, Ahmed F, Babazadeh D, FangFang X, Ghazani FM, WenHUA 1,xIAOhui Z. Chlorogenic acid( CGA): A pharmacological review and call for further research. Biomed Pharma. 2018; 97: 67- 74.

15. Zhou W, Liu S, Zhou X, Hanning M, Rupf S, Feng J, Peng $\mathrm{X}$, Cheng L. Modifying Adhesive Materials to Improve the Longevity of Resinous Restorations. Int J Mol Sci. 2011; 20: 723-743.

16. Souza de Moraes IQ, Gomes do Nascimento T, Thomás da Silva A, Santos Silva de Lira LM, Parolia A, Celerino de Moraes IC. Inhibition of matrix metalloproteinases: a troubleshooting for dentin adhesion. Restor Dent Endod. 2020;45(3):1-20.

17. Chung S, Leonard JP, Nettleship I, Yee Soong JK, Martello DV, Chyu MK. Characterization of $\mathrm{ZnO}$ nanoparticles suspension in water. Effectiveness of ultrasonic dispersion. Powder Tech. 2009; 194(1): 75- 80.

18. Shadman N, Ebrahim SF, Lahijani EM, Ghaderi A. Shear bond strength of different adhesive systems to normal and caries affected dentin. J Oral Health Oral Epidemiol. 2015; 4(2): 87- 93.

19. Shin JH, Jang JH, Park SH, Kim E. Effect of mineral trioxide aggregate surface treatments on morphology and bond strength to composite resin. J Endod. 2014; 40(8): 1210- 1216.

20. Yang H, Guo J, Deng D, Chen Z, Huang C. Effect of adjunctive application of epigallocatechin-3-gallate and ethanol-wet bonding on adhesive-dentin bonds. J Dent. 2016; 44 :44-49.

21. Baracco B, Fuentes MV, Garrido MA, González-López $\mathrm{S}$, Ceballos L. Effect of thermal aging on the tensile bond strength at reduced areas of seven current adhesives. Odontology. 2013; 101: 177-185.

22. Anuwongnukroh N, Dechkunakorn S, Arunkul J, Wichai W. Failure site and ARI score of rebonded brackets using No-Mix adhesive resins. Key Eng Mater. 2016; 689: 68- 72. 
23. Baroudi K, Rodrigues JC. Flowable resin composites: A systematic review and clinical considerations.J Clin Diagn Res. 2015; 9(6):18- 24.

24. Bektas OO, Eren D, Akin EG, Akin H. Evaluation of a self-adhering flowable composite in terms of micro-shear bond strength and microleakage. Acta Odontol Scand 2013;271:541-546.

25. International Standards Organization (ISO). Dentistry Testing of adhesion to tooth structure. ISO/TS 11405:2015.

26. D Lafuente. SEM analysis of hybrid layer and bonding interface after chlorhexidine use. Oper Dent. 2012; 37: 172-180.

27. BarouDi KS, C. roDrigue J. Flowable resin composites: A systematic review and clinical considerations. J Clinic and Diagnost Res. 2015; 9(6): 18- 24.

28. Gale M, Darvell BW. Thermal cycling procedure for laboratory testing of dental restorations. J Dent1999; 27(2): 89- 99.

29. Bahari M, Oskoee SS, Chaharom MEE, Gholizadeh S, David F. Effect of accelerated aging and double application on the dentin bond strength of universal adhesive system. Dent Res J. 2021; 6: 18- 25.

30. Ćurko N, Tomašević M, Bubalo MC, Gracin L, Redovniković IR, Ganić KK. Extraction of Proanthocyanidins and Anthocyanins from Grape Skin by Using Ionic Liquids. Food Technol Biotechnol. 2017; 55 (3); 429- 437.

31. Greco KY, Francis L, Huang H, Ploeg R, Boccaccini AR, Ansari T. Is quercetin an alternative natural crosslinking agent to genipin for long term dermal scaffolds implantation? J Tissue Eng Regen Med. 2018; 12 (3): 1716- 1724.

32. Nallamuthu I, Devi A, Khanum F. Chlorogenic acid loaded chitosan nanoparticles with sustained release property, retained antioxidant activity and enhanced bioavailability. Asian J Pharma Sci. 2015; 10(3): 203- 221.

33. Elmobsher KA, Niazy MA, Motawea IT, Sultan MS. Effect of natural cross-linkers on shear bond strength to dentin after storage in different media. ADJ-for Girls.2017; 4(3): 223-229.

34. Sadek FT, Castellan CS, Braga RR, Mai S, Tjäderhane L, Pashley DH, Tay FR. One-year stability of resin-dentin bonds created with a hydrophobic ethanol-wet bonding technique. Dent Mater.2010; 26: 380-386.

35. Park YS, Jeon MH, Hwang HJ, Park MR, Lee SH, Kim SG, Kim M. Antioxidant activity and analysis of proanthocyanidins from pine (pinus densiflora) needles. Nutr Res Pract. 2011; 5 (4): 281- 287.

36. Luukko K, Kettunen P, Fristad I, Berggreen E. Cohen's Pathways of the pulp. Tenth edition. (Chapter 12) Structure and Functions of the Dentin-Pulp Complex. 2011:450- 452.

37. Carvalho C, Fernandes FP, Freitas V, Franca FM, Basting RT, Turssi CP, Amaral FL. Effect of green tea extract on bonding durability of an etch- and- rinse adhesive system to caries affected dentin. J Appl Oral Sci. 2016; 24 (3): 211- 217.

38. El- Baz MA, Aboulenien K. The effect of green tea extract as a matrix metalloproteinase inhibitor on the bond strength of resin composite.EDJ.2018; 64: 2807- 2817.

39. Epasinghe DJ, Yiu CKY, Burrow MF, Tay FR, King NM. Effect of proanthocyanidin incorporation into dental adhesive resin on resin- dentin bond strength. J Dent. 2012; 40(3): 173- 180 .

40. Wildermuth SR, Young EE, Were LM. Chlorogenic acid oxidation and its reaction with sunflower proteins to form green coloured complexes. Comprehens Rev in Food Sci and Safe.2016; 15:829- 843.

41. Bumrungruan C, Sakoolnamarka R. Microshear bond strength to dentin of self-adhesive flowable composite compared with total-etch and all-in-one adhesives. J Dent Sci. 2016; 11(4): 449- 456. 